\section{Nobel prizes announced for physics and for chemistry}

THIS year's award of the Nobel prize for physics recognizes fundamental experiments which belong almost to the prehistory of the fast-moving field of highenergy physics. The recipients of the prize are Leon Lederman, Melvin Schwartz and Jack Steinberger, all Americans, and the work cited is their invention, in the early 1960 s, of a way to generate a neutrino beam in the laboratory and their subsequent discovery of the muon neutrino.

Any surprise at the award derives from its belatedness rather than the stature of the winners. Lederman, Schwartz and Steinberger, according to the gossip that passes around high-energy physics departments, had appeared on the short-list numerous times, but with prizes having already been awarded for more recent discoveries, there was a general feeling that the three had run out of chances. Their win this year has been applauded by others in experimental high-energy physics as deserved recognition of basic work.

In the late $1950 \mathrm{~s}$, theoretical understanding of the weak interaction (responsible for radioactive beta-decay) was limited by the inability to do experiments in which its effects could be separated from those of the strong and electromagnetic interactions. At Columbia University, the three physicists jointly devised a way to produce and detect a beam of neutrinos, particles influenced by the weak interaction and no other.

By smashing an energetic proton beam into a beryllium target, they first created a stream of nuclear fragments containing a large proportion of pions. Each pion then decays in flight into a neutrino and another charged particle. The second, neutrinos from the nuclear debris. This they achieved by erecting a massive steel wall, made of scrap steel from battleships, behind which they built a 10-ton spark chamber to detect secondary charged particles produced by collisions between

The unexpected bonus of this experiment, whose unprecedented size made it the precursor of the vast experimental setups now routinely built at accelerators, was the discovery of two different neutrino types. At the time only one neutrino, produced in accompaniment with an electron in beta-decays, was recognized, but in the new experiment it was found that the charged particle that accompanied the spark-chamber detection was more often a muon than an electron, and a series of experiments soon established that the muon neutrino was a species distinct from the previously known electron neutrino.

\section{Washington} equally important step was to separate the neutrinos and atoms in the chamber.
This was a first indication of the nowstandard recognition that elementary particles, including quarks, neutrinos and their accompanying charged partners, fall into three parallel but separate families.

Schwartz now runs his own computer communications company in Mountain View, California, but Lederman, director of the Fermi National Accelerator Laboratory in Illinois, and Steinberger, a physicist at CERN, Geneva, are still active in high-energy physics. Lederman is an active supporter of the Superconducting Super Collider, the proposed 50-milecircumference proton-proton collider. Under his tenure, Fermilab has run a successful programme that brings high-school students into the laboratory for summer courses.

David Lindley

\section{London}

ELUCIDATION of the structure of a protein complex with its "body immersed in a lipid bilayer and its head and legs in water" has won Hartmut Michel, Johann Deisenhofer and Robert Huber this year's Nobel prize for chemistry. The structure is the membrane-bound photosynthetic reaction centre of purple bacteria, which converts the energy of a photon into the potential to synthesize organic molecules.

Not only is the solution of the structure an impressive technical feat, but reaction centres are one of the most important protein structures in biology. The complex of different proteins within the centre is the heart of the photosynthetic reaction.

Crystallization of membrane proteins was a goal that had been sought by many, but Hartmut Michel, working in the division of Dieter Oesterhelt at the Max Planck Institute for Biochemistry at Martinsried, Munich, made a crucial breakthrough in 1981 by devising a method to produce large, well-ordered crystals of the reaction centre of the purple bacterium Rhodopseudomonas viridis.

The year before, two other membrane proteins had been crystallized for the first time, but technical problems prevented the arrangement of the atoms within the crystals from being determined. It had previously been difficult to isolate membrane proteins because the detergent necessary to dissolve the protein away from the lipid cell membrane tended to denature the protein itself. But a new detergent, octylglucoside, allowed threedimensional crystals of two protein complexes to be made: porin, a protein that forms pores in cell membranes; and bacteriorhodopsin.

The race was on to make three-dimensional crystals of a membrane protein large enough to resolve its structure in atomic detail using X-ray crystallography. Michel was the first to make such crystals, not of any of these proteins, but of the bacterial reaction centre.

Once Michel had obtained large threedimensional crystals of the reaction with Robert Huber, head of the laboratory, and Johann Deisenhofer, a staff scientist.

Their first results, published in 1984 centre, he began his fruitful collaboration

\section{IMAGE UNAVAILABLE FOR COPYRIGHT REASONS}

Top, Lederman (left), Schwartz and Steinberger, discoverers of the muon neutrino. Bottom, Deisenhofer (left), Huber and Michel, first to solve the structure of a membrane protein. 
(see below) showed that the central portion of the reaction centre consists of a 50 $\AA$ A-long cylinder and that the whole complex has a diameter of $140 \AA$.

In 1985, Michel and his collaborators reported the molecular structure of the whole reaction centre obtained from analysing the X-ray diffraction pattern of the crystals, emerged with great clarity. The structure confirmed predictions about how energy transfer works as well as revealing unusual features.

In the photosynthetic reaction, light energy is absorbed by electrons in pigment molecules surrounding the reaction centre complex in the membrane. The energy of the photon is rapidly transferred to the reaction centre, exciting the bacteriochlorophyll which then gives an electron to an acceptor. Earlier this year, G. Fleming et al. (Nature 333, 190; 1988) identified the acceptor as the bacteriopheophytin in the reaction centre complex. This electron transfer produces energy which is used by the complex to oxidize water, releasing oxygen. The other products are hydrogen and electrons, which reduce carbon dioxide to organic compounds.

Since 1985, techniques such as sitedirected mutagenesis have revealed more details about how the reaction centre works. And although the Nobel-prizewinning work holds out great promise for the elucidation of the structures of other membrane proteins, these hopes have not yet been realized. None of the membrane protein complexes crystallized in 1980 has yet been seen at atomic resolution

The Nobel-prizewinning team separated earlier this year; Michel moved to the Max-Planck Institute for Biophysics at Frankfurt, and Deisenhofer to the Howard Hughes Medical Institute at Dallas.

Maxine Clarke

An editor's nightmare is to reject a Nobel-prizewinning paper. Rejected authors not infrequently promise that the nightmare will come true. Hartmut Michel did not issue such a warning when we declined to publish his report of the successful crystallization of the photosynthetic reaction centre, saying that we looked forward to the time when the crystal yielded structural information.

When the first such information - on the bacteriochlorophylls and other prosthetic groups in the complex - became available, Michel and his colleagues published it in the Journal of Molecular Biology $(\mathbf{1 8 0}, 385 ; 1984)$. But when the structure of the protein subunits emerged, allowing the complete description of the reaction centre, Nature was delighted to be able to offer to publish it $(\mathbf{3 1 8}, 618 ; 1985)$.

Rejection of Hans Krebs' discovery of the tricarboxylic acid (or Krebs') cycle, a pivot of biochemical metabolism, remains Nature's most egregious error (as far as we know).

\section{Soviet academy rights one wrong but stands accused by Legasov}

\section{London}

Academician Andrei Sakharov was last week elected to the presidium of the Soviet Academy of Sciences, by a vote of 234 to 84 . His election took place during a threeday general meeting of the academy, devoted to the role of science in perestroika and the election of a younger leadership for the academy. Before the meeting, academy president Dr Gurii Marchuk said that a 50 per cent 'renewal' of the leadership was planned, to bring in young scientists, including five new vicepresidents.

In terms of the Gorbachev era, however, Academician Sakharov, at 67, hardly qualifies as 'young' and his well-deserved, even if belated, election to the presidium seems rather a redressing of an old injustice. Yu. A. Osipyan (physics), O.M. Nefedov (chemistry), R.V. Petrov (biology), N.P. Laverov (Earth scicnces) and V.N. Kudryavtsev (social sciences) were eventually elected vice-presidents.

Marchuk's keynote speech stressed the

\section{Poor return from India's science effort}

\section{New Delhi}

NEw statistics from the Indian Department of Science and Technology explode the myth that India comes third in national rankings of the number of working scientists. Although India boasts an estimated four million people with training in science, the report shows that a mere 85,309 are working on research and development. Of this number, just 4,375 are women.

Among the 241,000 persons employed at Indian research institutions, only one in four is a researcher. The remainder are administrative and auxiliary staff.

The report estimates that India spent 28,655 million rupees ( $£ 2,000$ million), or 1.1 per cent of its gross national product, on research and development in 1986-87, a 29 per cent rise over the previous year. About a third of the budget was spent on research activities related to defence. Industrial production and energy sectors received 12 and 10 per cent, respectively and transport and communications around 4 per cent.

The report notes that industrial research and development has increased, largely due to liberal financial incentives from the government. The private sector provides close to 20 per cent of expenditure. But the report warns that output is not commensurate with investment. The number of patents filed by Indian citizens has been declining since 1977 . K. S. Jayaraman role of science in developing the concept of a state that would reflect "all the values of the socialist order and, first and foremost, concern for the human being".

Yet, ironically, only a few days before the meeting, an article in Pravda suggested that conservatism within the academy may have played a significant role in the suicide of Academician Valerii Legasov last April. According to the inquest, Legasov took his life in a state of depression, while popular rumour associates his death with the high doses of radiation he received while overseeing the Chernobyl clean-up. Pravda, however, suggested that the academy old guard added to his worries. In sprng 1987, when the academy voted on the appointment of a new director of the Jurchatov Institute of Atomic Energy, Legasov, although chief deputy director, was voted down by 129 to 100 , a disappointment which, Pravda said, "shattered" him.

His efforts to publicize the neglect of safety training and general corner-cutting that lay behind the Chernobyl catastrophe seemed to have no effect. Fellow scientists, Pravda said, dismissed his views with phrases such as "Legasov does not follow the principles of Kurchatov". He was told that he would receive the title of Hero of Socialist Labour for his work at Chernobyl, but then learned that no one from the Kurchatov Institute would be so honoured, as the scientists there were considered to be to some extent responsible for what happened.

Finally, on 26 April 1988, the second anniversary of Chernobyl, a plan worked out by Legasov for reactivating Soviet chemistry after the 'stagnation' of the Brezhnev era was rejected by senior academicians with the command that "We won't let a mere lad lead us". (Legasov was 52.) The following day, he committed suicide. His article on Chernobyl "It is my duty to speak out. . ." finally appeared in Pravda a month after his death.

Legasov's death may be construed as over-reaction to professional disappointment while in an abnormal state of health. Nevertheless, the Pravda account gives an unusual insight into the problems of perestroika within the academy. The central committee of the Communist Party of the Soviet Union has passed a resolution to commemorate Legasov's name (by calling streets, schools and possibly a research vessel after him) - and the recent Seventh World Conference on Hydrogen Energy in Moscow opened with a minute's silence in his memory. But the best tribute to his memory, Pravda concluded, would be the implementation of his ideas, on energy, ecology, safety and perestroika.

Vera Rich 